\title{
La participación económica de los socios cooperativos: cooperativas tradicionales, autogestionarias y cogestionarias de Costa Rica
}

\author{
(The economic participation of cooperative members: \\ traditional cooperatives, self-managed and co-managed \\ cooperatives of Costa Rica)
}

Roxana Sánchez Boza ${ }^{1}$

Universidad Nacional de San José de Costa Rica (Costa Rica)

Sumario: Introducción. 1. El tercer principio cooperativo conocido como participación económica de los socios. 2. El derecho a la participación de los socios en el capital social. 2.1. Medios de reposición del capital social por efecto de pérdidas. 2.2. Protección del capital social. 2.3. Límites a la participación conforme aportes en el capital social cooperativo. 3. De las reservas legales y voluntarias, destino y distribución de excedentes. 3.1. Destino de excedentes originados en la participación en organismos cooperativos de integración. 3.2. Distracción de fondos a fiesta Navidad. 4. De las cooperativas de autogestión. 4.1. Deberes asociados autogestionarios en relación con su derecho a los excedentes. 4.2. Confusión de oficinas públicas Ministerio de trabajo en cuanto el funcionamiento de las cooperativas autogestionarias: pagos cuota patronal y seguridad social y el derecho del asociado autogestionario a ejercer el retiro. 5. Normativa especial en la distribución de excedentes en cooperativas cogestionarías. 5.1. Distribución de excedentes provenientes de la gestión de una cooperativa cogestionaría integrada por el Estado y trabajadores. 5.2. Distribución de excedentes provenientes de la gestión de una cooperativa cogestionaría integrada por productores y trabajadores. 6. Pago de impuesto de la renta por los excedentes y sus excepciones. 7. Derechos económicos del asociado retirado o excluido de la cooperativa. 8. Derecho al retiro cooperativa autogestionaria. 9. Inicio del plazo para el pago de los aportes a asociados retirados en una cooperativa. 10. Desafiliación y conservación del patrimonio cooperativo. 11. Sobre derecho a retiro sin previo pago de deudas. 12. Devolución de aportes a asociado en cooperativa cogestionaría. 13. Conclusiones. 14. Bibliografía.

1 Email: metanoia500@yahoo.es 
Summary: 0 . Introduction. 1 . The third cooperative principle known as economic participation of members. 2. The right to participation of the members in the share capital. 2.1. Means of replacement of social capital due to losses. 2.2. Protection of social capital. 2.3. Limits on participation according to contributions in the cooperative social capital. 3. Legal and voluntary reserves, destination and distribution of surpluses. 3.1. Destination of surpluses originated in the participation in cooperative organisms of integration. 3.2. Distraction of funds to Christmas party. 4. Self-management cooperatives. 4.1. Self-managed associated duties in relation to their right to surpluses. 4.2. Confusion of public offices Ministry of labor regarding the operation of self-managed cooperatives: employer and social security payments and the right of the self-managing member to exercise retirement. 5. Special regulations on the distribution of surpluses in co-management cooperatives. 5.1. Distribution of surplus from the management of a co-managed cooperative integrated by the State and workers. 5.2. Distribution of surplus from the management of a co-managed cooperative integrated by producers and workers. 6. Payment of income tax for surpluses and their exceptions. 7. Economic rights of the member retired or excluded from the cooperative. 8. Right to self-managed cooperative retirement. 9. Start of the term for the payment of contributions to members retired in a cooperative. 10. Disaffiliation and conservation of cooperative heritage. 11. On the right to withdrawal without prior payment of debts. 12. Refund of contributions to members in self-managed cooperative. 13. Conclusions. 14. Bibliography.

Resumen: Costa Rica mantiene su ley cooperativa que data de 1968, con algunas reformas que no han cambiado su letra en cuanto al tratamiento de los Principios Cooperativos. La legislación cooperativa se ha enriquecido, en las últimas décadas, con la participación de la Procuraduría General de la República, de los tribunales y sobre todo con el análisis de la Ley cooperativa, realizado por el Instituto Nacional de Fomento Cooperativo, en su tarea de aclarar las dudas que los entes cooperativos y los cooperativistas le plantean, como producto de su vida diaria en sus organizaciones cooperativas.

Con base en las fuentes mencionadas se comunica la posición de la legislación cooperativa costarricense frente al tercer Principio Cooperativo relacionado con la participación económica de los socios, según las diferentes partes que tiene ese principio y cómo afecta la relación de los asociados con la cooperativa, así como los derechos que derivan de la misma, en el campo económico.

Palabras clave: cooperativas, derechos económicos, tipos de cooperativas, excedentes, decisiones de entes públicos.

Abstract: Costa Rica maintains its cooperative law dating back to 1968, with some reforms that have not changed its letter regarding the treatment of 
co-operative principles. The cooperative legislation has been enriched, in recent decades, with the participation of the attorney General of the Republic, the courts and especially with the analysis of the Cooperative law, conducted by the National Institute of Development Cooperative, in their task of clarifying the doubts that cooperative entities and co-operatives propose to them, as a product of their daily lives in their cooperative organizations.

Based on the sources mentioned, the position of the costa rican cooperative legislation is communicated against the third cooperative principle related to the economic participation of the partners, according to the different parts that this principle has and how it affects the relationship of the associates with the cooperative, as well as the rights that derive from it, in the economic field.

Keywords: cooperatives, economic rights, types of cooperatives, surpluses, decisions of public entities. 


\section{Introducción}

En Costa Rica, la legislación cooperativa data de 1943, año en el cual fue promulgado el Código de Trabajo, como una de las leyes más importantes que nacieron de la política social de los cuarenta. Se integró el Título V, De las organizaciones Sociales, Capítulo III De las cooperativas, que junto con la normativa para los sindicatos, hizo realidad muchos de los proyectos de protección del sector laboral del país.

Fue necesario el paso de más de 20 años para que la legislación cooperativa obtuviera su independencia, por medio de la Ley de asociaciones cooperativas, N. 4179 y poco a poco se fueron promulgando otras leyes que complementaron el panorama político, económico, social y jurídico del Cooperativismo costarricense.

Sin embargo, la reforma integral a Ley mencionada, aun espera en los archivos de la Asamblea Legislativa, porque si bien se han dado diferentes propuestas, dentro de las cuales, una de las más importantes fue el proyecto de ley para incorporar las nuevas tendencias del Cooperativismo mundial, aprobadas en 1995, cuando la Alianza Cooperativa Internacional convocó al Cooperativismo mundial a revisar y renovar sus bases doctrinarias y filosóficas; en Costa Rica no se logró el consenso entre las fuerzas políticas existentes en el Poder Legislativo y el mismo Cooperativismo. Otra propuesta que también se incorporó a los aires de renovación legislativa, derivó de las múltiples novedades incluidas en la Ley marco para cooperativas de América, primero desarrollada por la Organización de cooperativas de América, y cuya bandera, luego elevó la $\mathrm{ACl}$.

Además de los temas comunes al contenido del tercer principio cooperativo sobre la participación económica de los asociados, se incluye la diferenciación operada por la modificación a la Ley de asociaciones cooperativas, en 1982, por la cual nacen las cooperativas autogestionarias y las cogestionarias, que tienen un tratamiento diferente para el aspecto de la distribución de los excedentes y las reservas sociales.

De acuerdo con ese panorama, este ensayo se basa en la normativa actual, que data esencialmente de 1968 y sus reformas, algunos pronunciamientos de la Procuraduría General de la República; fallos de los tribunales de Justicia y algunos criterios emitidos por el Instituto Nacional de Fomento Cooperativo, en Costa Rica. 


\section{El tercer principio cooperativo conocido como participación económica de los socios}

Han pasado más de 25 años desde que el Cooperativismo mundial fue convocado, en Manchester Inglaterra, para revisar el contenido de los Valores y Principios Cooperativos, ambos grupos de preceptos y guías del Cooperativismo, fueron objeto de análisis en cuanto su vigencia y las nuevas necesidades del Cooperativismo. Muchos países han incorporado las modificaciones, en sus legislaciones, dentro de las cuales se cuentan países latinoamericanos, otros países del ámbito de América Latina, también aprovecharon las guías ofrecidas por la Ley Marco para Cooperativas de América, por ejemplo la legislación cooperativa panameña, lo hizo dos años después, en 1997. Costa Rica, tiene esa deuda pendiente, y por ello, es necesario partir de la norma general de interpretación e integración jurídica, que se encuentra en el artículo 131 de la LAC, para dar vigencia al tercer principio cooperativo, en toda su extensión, en el tanto que autoriza a aplicar los principios generales del Derecho Cooperativo, cuando se presentaren lagunas jurídicas para resolver casos no previstos en la escritura social o los estatutos de la respectiva asociación cooperativa.

El texto del Tercer Principio plasmado en la Declaración de 1995 de la $\mathrm{ACl}$ se refiere a dos derechos esenciales de los socios:

- el derecho a la participación de los socios en el capital social

- el derecho a la distribución equitativa de los excedentes.

Gadea, Sacristán y Vargas explican el principio mencionado, disgregándolo en sus diversas partes:

Este principio describe tanto cómo participan los socios en el capital como la forma en que deben distribuirse los excedentes. Es digna de ser resaltada la afirmación que señala que «los socios contribuyen equitativamente al capital de las cooperativas y lo gestionan de forma democrática, dado que, por una parte, hace hincapié en la necesidad de que los socios aporten capital a su cooperativa y, por otra, permite que las diferentes legislaciones exijan que cada socio aporte, sin que ello tenga trascendencia en el proceso de adopción de decisiones, cantidades distintas, según su capacidad económica. $(40-41)^{2}$

2 GADEA, E., SACRISTÁN, F. y VARGAS, C. (2009). Régimen jurídico de la sociedad cooperativa del siglo XXI. Realidad actual y propuestas de reforma. Ed. Dykinson S.L., Madrid. Pgs. 40 y 41. 


\section{El derecho a la participación de los socios en el capital social}

En Costa Rica, la Ley de Asociaciones Cooperativas, en adelante LAC, contempla ese principio distribuido en varios artículos. En el Capítulo VI se refiere al patrimonio social y en el Capítulo VII se refiere a los saldos y excedentes. El patrimonio social es calificado como variable e ilimitado y dentro de sus elementos se encuentra el capital social (art. 66 inciso a), cuya composición tiene un variado origen (artículo 67) como son las aportaciones de los asociados en un amplio abanico de posibilidades, porque pueden ser bienes muebles e inmuebles, derechos; o si fuera en trabajo, industria, capacidad profesional o fuerza productiva, también puede provenir de sus familiares.

En el segundo párrafo del artículo citado, se indica que los estatutos de cada cooperativa, establecerán un método para valorar las aportaciones que no sean en dinero efectivo, cuando ingrese el nuevo asociado.

Los aportes al capital social están representados por certificados de aportación de igual valor nominal (art. 67 ibidem). Y desde el principio de la constitución de la entidad cooperativa, debe ser comunicado al Ministerio de Trabajo y Seguridad Social, como uno de los requisitos de autorización de inicio de las actividades cooperativizadas (art. 32), el monto de los certificados de aportación suscritos y los que hubiera pagado cada uno de los asociados. Los estatutos deberán contener sobre el tema de patrimonio social y certificados de aportación, según artículo 34, lo siguiente:

d) El monto del patrimonio social inicial, el número y el valor de los certificados de aportación en que se divide y la época y forma de pago, excepto en las cooperativas de autogestión.

k) La forma de traspasar los certificados de aportación y las limitaciones que al efecto se estipulen, excepto en las cooperativas de autogestión.

En el caso de las cooperativas de autogestión, el artículo 114 de ley cooperativa indica que los certificados de aportación provienen de las inversiones productivas que realicen los asociados con sus cooperativas.

Ese contenido estatutario tiene relación directa con la responsabilidad limitada de las organizaciones cooperativas, las cuales atienden sus compromisos con el haber social y también los asociados hasta por el monto de los aportes suscritos, según el artículo 31, que encuentra su complemento en la letra del artículo 71 que ofrece los límites de la responsabilidad cuando se trata de embargo de los certificados de 
aportación de los asociados, por parte de los acreedores de la cooperativa, dentro de los límites del capital y responsabilidad sociales. Dichos acreedores podrán ejercer los derechos de la cooperativa, relativos a los aportes de capital no pagados, siempre que fueran exigibles y necesarios para el pago de las deudas sociales. Este privilegio otorgado a los referidos acreedores no excluye los derechos preferentes de la cooperativa, cuando esta tenga que proceder contra los asociados, excepto en las cooperativas de autogestión regidas por las disposiciones capítulo XI de la LAC, y de cuyo régimen especial se hace referencia más adelante.

El Capital Social de la cooperativa se representa en forma individual para cada asociado, en certificados de aportación, los cuales están regulados en el artículo 68 LAC, y deben cumplir con requisitos mínimos:

- ser nominativos, indivisibles, transmisibles únicamente a través del Consejo de administración de la cooperativa,

- cumplir con los requisitos y condiciones que fijen los estatutos;

- contener las especificaciones y leyendas que acuerde el Consejo de administración;

- estar clasificados en series numeradas una por cada emisión correspondiente al cierre del respectivo ejercicio económico.

- el monto de los certificados de aportación no debe ser inferior a $€ 50,00$ (\$0.9) ni superior a $€ 200,00$ (\$0.27) salvo el caso de las cooperativas escolares, en las que podrá ser menor y será fijado por la asamblea.

También la Ley Regulación de Intermediación Financiera de organizaciones Cooperativas N. 7391, en el Capítulo III, sobre el Capital social, en el artículo 11 se establece que el mismo está constituido con los certificados de aportación, con iguales características que las establecidas en la LAC, eso sí se agrega un párrafo que aclara el derecho de participación en los órganos sociales de la cooperativa por parte de los socios: Dichos certificados representan la participación patrimonial de los asociados en la cooperativa y les confiere el derecho a voz y voto, de conformidad con la ley. Y el artículo 12 se indica que la tasa de retorno que podrán devengar será fijada por el Consejo de Administración de cada cooperativa. En el artículo 13 se establecen los mismos derechos para la devolución del dinero que representan los certificados de aportación, que para el resto de las cooperativas. Eso sí acentúa la situación contemplada en el artículo 72 de LAC sobre el control de los aportes al capital, con el fin de evitar situaciones financieras difíciles en el futuro y se autoriza la inclusión, en los estatutos de porcentajes fijos como monto máximo de los aportes económicos que puedan desti- 
narse, al concluir cada ejercicio económico, para cubrir el monto de los aportes hechos por los asociados que hubieren renunciado. En el artículo 68 y sus correspondientes derechos, en el inciso j) sobre la forma y reglas de distribución de los excedentes obtenidos durante el respectivo ejercicio económico; inciso l) sobre las garantías que deberá rendir el personal encargado de la custodia de los bienes y fondos de la asociación.

Otra característica del capital social cooperativo es el pago de un interés limitado a los aportes hechos por el asociado, según inciso f) artículo 3 de la ley en estudio. Ese interés lo fija la asamblea de cada cooperativa, sujeto a la limitación legal de no exceder al monto establecido en el Banco Central de Costa Rica, para los bonos bancarios. El pago es únicamente sobre las sumas hechas efectivas por los asociados y solo podrán cubrirse con cargo a los excedentes obtenidos por la cooperativa. En las cooperativas de autogestión dicho interés será fijado por la Comisión Permanente de Cooperativas de Autogestión (artículo 74 LAC).

\subsection{Medios de reposición del capital social por efecto de pérdidas}

En caso de disminución del patrimonio social de la cooperativa, por pérdida en el ejercicio de las operaciones sociales, podrá ser repuesto con fondos pertenecientes a la reserva legal, según lo dispongan los estatutos o lo acuerde la asamblea. Si la reserva legal no alcanzare para cubrir las pérdidas, estas se cargarán en forma proporcional al capital social pagado o suscrito según lo dispongan los estatutos en cada caso, dispone el artículo 70 de la LAC.

Los certificados de aportación, depósitos, participaciones o derechos de cualquier clase que correspondan a los asociados de una cooperativa, quedan vinculados preferentemente y desde su origen, a favor de esta, como garantía de la obligación u obligaciones que aquellos pudieran llegar a tener con la asociación.

\subsection{Protección del capital social}

En Costa Rica, la protección del capital social forma parte de los derechos económicos de los asociados, que se logra porque existe un comité de vigilancia electo por la asamblea, o a la auditoría mencionada, que deben realizar el examen y la de todas las cuentas y operaciones realizadas por la cooperativa. También deberá informar a la asamblea 
lo que corresponda, previa entrega de resultados a los asociados (artículo 49 LAC).

Un ejemplo del fortalecimiento del capital social cooperativo se encuentra en el acuerdo de Asamblea de una cooperativa de taxis, que obligó a los miembros de la misma a llenar el tanque con combustible, al menos una vez al día, bajo la sanción por el incumplimiento de la aplicación de una sanción de no recibir comunicaciones por medio de la frecuencia de radio de los servicios solicitados por los clientes por un espacio de 24 horas. Uno de los asociados que se consideró afectado interpuso un recurso de amparo ante la Sala Constitucional, la cual por Voto 11629-2010. Considerando V, declaró sin lugar el recurso, dado que se consideró que no existía ningún derecho fundamental afectado. Otra situación relacionada con la protección del capital social cooperativo y los límites de su transmisibilidad, fue conocida en el Instituto nacional de fomento cooperativo (INFOCOOP), por el reclamo de la totalidad de una suma invertida por una pareja de asociados, unidos en matrimonio, quienes luego se separaron. La inversión se había realizado dado que por la apertura de un Almacén de insumos, uno de los requisitos para dar crédito era que el asociado tuviese capital en su haber. Por ello, la pareja de asociados había aportado 2 millones de colones, distribuidos en mayor suma a favor de la esposa y el resto a nombre del marido. La asociada reclamó que se le debía pasar a su nombre todo el dinero inversión. El INFOCOOP confirmó la decisión del gerente de la cooperativa, indicando que la transmisión de certificados de aportación debe ser por mutuo acuerdo y no en forma unilateral (SC-14081404CO-2015).

\subsection{Límites a la participación conforme aportes en el capital social cooperativo}

También es importante tomar en cuenta que la participación económica de un asociado de una cooperativa, como es el monto de los certificados de aportación, o los excedentes obtenidos, lo autoriza para intervenir directamente en la dirección y administración de los negocios sociales, salvo los derechos que tienen en las asambleas que al efecto se convoquen, según lo deja muy claro el artículo 87 ibidem, exigibles y necesarios para el pago de las deudas sociales. Este privilegio otorgado a los referidos acreedores no excluye los derechos preferentes de la cooperativa, cuando esta tenga que proceder contra los asociados, excepto en las cooperativas de autogestión que se regirán por lo que se establece en el capítulo XI. 


\section{De las reservas legales y voluntarias, destino y distribución de excedentes}

En el Capítulo VII, denominado De los saldos y excedentes, la LAC en armonía con el artículo 3, establece que las cooperativas no tien utilidades (artículo 78). Y que los saldos a favor que arroja la liquidación del ejercicio económico correspondiente, son ahorros o excedentes que pertenecen a sus miembros, producidos por la gestión económica de la asociación, y por ello no se pagará el Impuesto sobre la Renta. El excedente surge una vez realizada la liquidación en el inventario anual correspondiente, deducidos los gastos generales, las cargas sociales y las amortizaciones de todo género, constituyen el excedente o saldo del período respectivo (artículo 79).

Inicialmente, cuando se promulgaron las primeras normas de legislación cooperativa, los fondos eran únicamente para reserva legal, un $15 \%$ de los excedentes y u $12 \%$ para previsión social. Los fondos eran obligatorios e irrepartibles, y se denominaron de reserva legal y de previsión sólo cuando el fondo de reserva legal fuera equivalente a la tercera parte del capital suscrito actual, se podían constituir otros fondos de reserva, especiales con la cuota destinada a su formación (artículos 348 a 352 del Código de Trabajo de 1943).

Existe un orden para el destino de los excedentes:

- para constituir las reservas legales, la reserva de educación, la reserva de bienestar social y cualesquiera otras reservas establecidas en los estatutos;

- para cubrir las obligaciones provenientes de las cuotas de inversión;

- para pagar al Consejo Nacional de Cooperativas el 2\% de los excedentes, conforme con lo estipulado en el artículo 136 de esta ley;

- para pagar al Centro nacional de Educación Cooperativa hasta el $2,5 \%$ de los excedentes líquidos al cierre de cada ejercicio económico, porcentaje éste que, según el criterio del consejo de administración de cada cooperativa, podrá pagarse de la reserva de educación.

Los porcentajes correspondientes a la formación de reservas especiales se deben establecer en los estatutos de cada cooperativa, con excepción de las reservas legales con un mínimo del 10/\%, de bienestar social con un mínimo de $6 \%$ y de educación con un mínimo de $5 \%$, de los excedentes, según los artículos 81, 82 y 83 de la LAC. 
El fondo de reserva legal se debe destinar, tiene por objeto cubrir pérdidas imprevistas, debe ser permanente y no se podrá distribuir entre los asociados, ni en caso de disolución de la cooperativa. Cuando el fondo de la reserva legal equivalga a un tercio del capital suscrito actual, los incrementos posteriores, serán representados en nuevos certificados de aportación que si se distribuirán entre los asociados, excepto en las cooperativas de autogestión, en cuyo caso este monto pasará a formar parte del fondo de las cooperativas de autogestión. Este fondo de reserva legal podrá ser dedicado a diversas inversiones en bienes y derechos muebles e inmuebles, que por su naturaleza sean seguros, prefiriendo en primer término, operaciones financieras con los organismos superiores de integración cooperativa (artículo 81).

\subsection{Destino de excedentes originados en la participación en organismos cooperativos de integración}

Existen otros ingresos de las cooperativas que pertenecen a organismos de integración cooperativa, y han surgido dudas en los directivos de las cooperativas integradas a algún organismo, sobre ¿cómo deben las cooperativas contabilizar los excedentes que reciban de su organismo de integración?

Sobre dicho tema el AL 668-93 del 21 de setiembre de 1993 analizó la diferencia del destino de esos excedentes:

- En caso de existir una inversión en un organismo auxiliar dedicado a una actividad similar a la realizada por la Cooperativa, se consideró como una extensión de las actividades del giro principal de la cooperativa, es decir aquellas idóneas para cumplir con su objeto social. En consecuencia estos excedentes podrían ser distribuidos entre los asociados o capitalizados, según lo acuerde o determine la asamblea. Siempre y cuando la cooperativa esté legalmente autorizada — vía Estatuto Social — para desarrollar la actividad, lo anterior por cuanto el artículo 12 inciso f) de la LAC, que prohíbe a las cooperativas el desarrollo de actividades sin autorización legal.

- Ahora bien, si la cooperativa tiene una inversión permanente en un organismo auxiliar cuya actividad que no tiene ninguna relación con el objeto social de la Cooperativa, y su fin exclusivo es obtener una ganancia. Los ingresos obtenidos califican como beneficios indirectos» a que se refiere el artículo 82 párrafo tercero de la LAC y esos ingresos deben pasar a engrosar la reserva 
de educación, o bien, a una cuenta de superávit para fortalecimiento patrimonial de la cooperativa, no capitalizable ni distribuible entre los asociados.

Concluye el criterio que así se cumpliría con lo establecido en el artículo 3, inciso j) de la LAC, que obliga a todas cooperativas del país a respetar la irrepartibilidad de las reservas establecidas por ley y de los excedentes producidos por las operaciones con personas que, sin ser asociados, hubieran usado los servicios de la cooperativa y de los ingresos no provenientes de la función social de la cooperativa.

En cuanto la reserva de educación tiene como destino el sufragio, dentro de la zona de influencia de las cooperativas, de campañas de divulgación de la doctrina y los métodos cooperativos, cursos de formación y capacitación cooperativa, o a impartir educación general, de acuerdo con el reglamento respectivo elaborado por el INFOCOOP. Es ilimitada y se engrosa con los excedentes de no asociados y beneficios indirectos, así como aquellas sumas que no tuvieren destino específico, sin perjuicio de que ésta pueda incrementarse por otros medios; los intereses y las sumas repartibles que no fueren cobrados dentro del término de un año a partir de la fecha en que fue aprobada su distribución, caducarán a favor de la reserva de educación y reserva de bienestar social (artículo 82).

La otra reserva obligatoria es la denominada de bienestar social, destinada a los asociados, a los trabajadores de la asociación y a los familiares inmediatos de unos y otros, para ofrecerles ayuda económica y programas en el campo de la asistencia social, especialmente para aquellos servicios que no otorgue la Caja Costarricense de Seguro Social, o no estén contenidos en las disposiciones sobre riesgos profesionales. Esta reserva también será ilimitada; a su formación se destinará por lo menos un $6 \%$ de los excedentes anuales de las cooperativas, y para su uso, destino o inversión deberá contarse siempre con la aprobación de la asamblea.

\subsection{Distracción de fondos a fiesta de Navidad}

Sobre el destino de los fondos de la Reserva de Bienestar Social, en una cooperativa se aplicaron tales recursos a una fiesta de Navidad, ante la consulta del gerente de la cooperativa implicada, la Asesoría Legal del Instituto Nacional de fomento Cooperativo, MGS-584-412-2007, previa aclaración sobre la naturaleza jurídica y destino de tal Reserva, comunicó a la gerencia de la cooperativa que 
los recursos debían retornar a las cuentas de la reserva. Explicó en la siguiente forma:

Al respecto debe iniciarse manifestando que la LAC en sus artículos 82 y 83 define las Reservas de Educación y Bienestar Social como dos reservas independientes entre sí y que además gozan del carácter de ser permanentes irrepartibles e ilimitadas.

Con base en lo expuesto, debe manifestarse que la Cooperativa le aplicó erróneamente a la Reserva de Bienestar Social lo correspondiente al monto de gastos fiestas de fin de año» dado que como se señaló la misma debe emplearse en el campo de la asistencia social, especialmente, en aquellos servicios que no preste la Caja Costarricense del Seguro Social, o que no estén cubiertos por las disposiciones de riesgos profesionales.

\section{De las cooperativas de autogestión}

Las cooperativas de autogestión o de trabajo asociado así como las de cogestión, son modelos de distribución de la propiedad cooperativa introducido en 1982, en la legislación cooperativa. En las cooperativas de autogestión, los dueños de éstas son sus trabajadores, se conoce como la figura jurídica de asociado-trabajador y excepcionalmente, se puede incorporar a la cadena productiva, trabajadores no socios. En el Capítulo XI de la LAC, se definen a las cooperativas de autogestión como empresas organizadas para la producción de bienes y servicios, en las cuales los trabajadores que las integran, dirigen todas sus actividades y aportan directamente su fuerza de trabajo, con el fin primordial de realizar actividades productivas y recibir, en proporción a su aporte de trabajo, beneficios de tipo económico y social. Donde las unidades de producción destinadas al funcionamiento de estas, estarán bajo el régimen de propiedad social con carácter indivisible. Ver artículo 99.

Según el artículo 100 de la LAC, uno de sus principales objetivos es la canalización de los excedentes para el desarrollo de sus empresas y la generación de nuevas unidades productivas de semejante vocación y naturaleza, contribuyendo así, a crear nuevos puestos de trabajo y bienestar general.

Los asociados de las cooperativas de autogestión tienen derecho a recibir una remuneración no inferior al salario mínimo fijado para las distintas actividades que rigen para las empresas privadas. Cada cooperativa debe fijar en sus estatutos la relación entre la remuneración máxima y mínima de que disfrutarán sus socios, la cual no será en 
ningún caso superior a diez. La fijación anual de las remuneraciones deberá ser aprobada por la asamblea general de asociados y remitida luego a la Comisión Permanente de Cooperativas de Autogestión para su aprobación final.

En este tipo de cooperativas ha existido mucha confusión respecto de su condición laboral, pues algunos miembros se consideran trabajadores de las cooperativas, y hay instituciones que califican la relación asociativa, como una relación laboral subordinada. Por esas razones, la precisión sobre la naturaleza jurídica de las cooperativas de autogestión y la relación de sus asociados-trabajadores, por parte de la Procuraduría General de la República adquiere real importancia y ha sido plasmada en el Dictamen C-007-91 del 14 de enero de 1991, del cual se transcribe una parte:

Por medio de las cooperativas autogestionarias se procura la auto-organización de los trabajadores para la autodeterminación de sus intereses empresariales. Se trata de fomentar la participación de los trabajadores en los procesos de producción y trabajo, estableciendo un equilibrio y unidad entre trabajo y medios de producción, sea una nueva forma de propiedad social. Los asociados son propietarios tanto desde el punto de vista jurídico como económico, por lo que no se establece una relación laboral entre los asociados y su cooperativa. Si el asociado es propietario de la cooperativa, no puede ser considerado asalariado de ella, aun cuando le preste su fuerza de trabajo. En otras palabras, las cooperativas autogestionarias son organizaciones de trabajadores pero sobre estos no se establece una estructura superior que elimine la gestión de los asociados. Esta gestión de los intereses de la cooperativa es un poder deber de todos los asociados: deben ser los propios trabajadores quienes dirijan las actividades empresariales, por lo que no pueden limitarse a aportar su fuerza de trabajo. Por el contrario, les corresponde definir los planes de producción, el planificar el desarrollo económico y social de la organización, aprobar sus planes de producción y la distribución social e individual de los excedentes que no tengan un destino prefijado en la ley.

\subsection{Deberes de los asociados autogestionarios en relación con su derecho a los excedentes}

La ley mencionada, establece en relación con los excedentes netos, que deben destinarse a múltiples reservas y fines, hasta llegar a un $46 \%$ de sus ingresos anuales, con lo cual hay un mayor peso eco- 
nómico a cumplir que el resto de las cooperativas. Tales porcentajes se deben distribuir en la siguiente manera:

a) Obligatoriamente el $10 \%$ a constituir la reserva legal, por lo menos el $6 \%$ para el fondo de bienestar social y un mínimo de 15\% a realizar inversiones productivas que amplíen la capacidad económica de la empresa, siempre y cuando las inversiones cumplan con lo que establezca el reglamento de inversiones que elaborará la Comisión Permanente de Cooperativas de Autogestión. En caso de que no se realice la inversión, estos pasarán a reforzar el Fondo nacional de cooperativas de autogestión, para ser destinado a inversiones en ese mismo tipo de empresas. La empresa recibirá la tasa de interés que la Comisión Permanente de Cooperativas de Autogestión previa consulta con el Instituto Nacional de Fomento Cooperativo, fije para estos efectos.

El $4 \%$ a la formación de un fondo para la promoción y capacitación de empresas cooperativas de autogestión, que será manejado por la Comisión Permanente de Cooperativas de Autogestión. El 5\% se destinará al fortalecimiento del fondo nacional de cooperativas de autogestión. El 5\% para el financiamiento de las uniones, federaciones y confederaciones. El $1 \%$ para el Consejo Nacional de Cooperativas. El saldo será distribuido por decisión de la asamblea entre los socios, en proporción a su aporte de trabajo, para lo cual la empresa debe llevar un control de las horas trabajadas por sus socios, sirviendo dicho control de base para la distribución de los excedentes entre los mismos, según los estatutos de la empresa. Y cualquier otro fin establecido en los estatutos o que determine la asamblea (artículo 114 ibid.).

\subsection{Confusión de oficinas públicas Ministerio de Trabajo en cuanto el funcionamiento de las cooperativas autogestionarias: pagos cuota patronal y Seguridad Social y el derecho del asociado autogestionario a ejercer el retiro}

Por la relación de asociado trabajador de un miembro de cooperativa autogestionaria, algunas instituciones públicas como la Caja Costarricense de Seguro Social han insistido en la obligatoriedad de pago de las cuotas obrero patronales para efectos del Régimen de invalidez, vejez y muerte, que asegura la atención médica durante la relación laboral y una pensión al finalizar ésta. El Instituto nacional de fomento cooperativo ha reiterado tanto su posición opuesta como la sostenida por la PGR donde se niega tal obligación, como se puede extraer de la 
resolución SC-0058-1255-2011 (p. 6) que retoma las opiniones expresadas en el Dictamen C-007-91 del 14 de enero de 1991, que aclara que la relación existente entre una cooperativa autogestionaria y sus asociados no debe considerarse bajo ningún concepto como una relación obrero patronal. Dado lo anterior, las cooperativas autogestionarias no están obligadas al pago de las cuotas de seguro social y obrero patronales de sus asociados.

Además, en la misma resolución y en respuesta a otra de las consultas planteadas, el Instituto nacional de fomento cooperativo ha señalado que por todo lo anteriormente indicado, cuando se produce el retiro de un asociado, no es procedente cancelar los extremos laborales (preaviso y cesantía entre otros), sino más bien debe hacerse entrega de los extremos a que hace referencia el artículo 62 de la LAC, referidos a la devolución del capital social, así como los excedentes e intereses del último periodo, si los hubiera. Para evitar futuras confusiones sobre la naturaleza jurídica de la relación asociado-trabajador, se recomienda que frente al criterio de la Oficina Regional Brunca, de la Dirección Nacional de Inspección del Trabajo, debe recomendarse a la cooperativa entregarle copia del presente Oficio, con tal de que conozcan más a fondo la naturaleza jurídica de la relación asociativa en las cooperativas autogestionarias.

\section{Normativa especial en la distribución de excedentes en cooperativas cogestionarias}

Como se indicó en el anterior aparte, las cooperativas cogestionarias pueden tener como asociados a productores y trabajadores; trabajadores y el Estado, o bien, pueden haberse constituido en forma tripartita: productores, Estado y trabajadores.

En consulta al Instituto nacional de fomento cooperativo, el análisis de la pregunta sobre cómo se debe hacer la distribución de excedentes en cooperativas cogestionarias, según resolución SC-1077-944-2011, se debieron considerar varios artículos que regulan diversamente, esa distribución. A continuación se hace un resumen de cada uno.

5.1. Distribución de excedentes provenientes de la gestión de una cooperativa cogestionaria integrada por el Estado y trabajadores

El artículo 122 de la LAC, aclara el punto de partida para lograr la distribución: 
En las cooperativas de cogestión entre el Estado y los trabajadores, el porcentaje de los excedentes que corresponde a los trabajadores se fijará tomando en cuenta: la rentabilidad de la empresa, el valor agregado por el factor trabajo y las inversiones efectuadas por el Estado y por los trabajadores. En el caso de empresas ya existentes en manos del Estado cuyos excedentes estén financiando otras actividades de éste y que se transformen en cooperativas de cogestión Estado-trabajadores, deberá tomarse en cuenta además las necesidades que el Estado estuviera cubriendo con el producto de la operación de la empresa. El porcentaje de los excedentes que corresponda a los trabajadores deberá distribuirse entre todos los trabajadores, incluidos los trabajadores temporales cuya parte correspondiente del porcentaje de dicho excedente, se calculará con base en el trabajo aportado.

La anterior norma se complementa con el artículo 124 de LAC, que asigna a la Oficina de Planificación Nacional y Política Económica y el Instituto Nacional de Fomento Cooperativo, en consulta con el Consejo Nacional de Cooperativas y las cooperativas de cogestión, la reglamentación de ese tipo de cooperativas para determinar la distribución de excedentes, entre otros aspectos que se consideren necesarios.

\subsection{Distribución de excedentes provenientes de la gestión} de una cooperativa cogestionaria integrada por productores y trabajadores

El artículo 124 inciso c) de la LAC, aclara el punto de partida para lograr la distribución:

Para la distribución de excedentes en cooperativas de cogestión productores trabajadores se tomará en cuenta el monto de las aportaciones hechas por cada sector y el volumen de operaciones realizadas por cada sector con la cooperativa; esto último en el caso de los trabajadores, estará constituido por el valor agregado por el factor trabajo y en el de los productores por el total del insumo entregado a la cooperativa.

\section{Sobre el pago de Impuesto sobre la Renta por los excedentes y sus excepciones}

Este tema ha sido muy tratado en anteriores entregas de la autora al Boletín, sin embargo, es importante resaltar que debido a la califi- 
cación de las cooperativas costarricenses como organizaciones sin fin de lucro, se les reconoce la exención del pago del impuesto de la renta en los excedentes, salvo cuando sean distribuidos entre los asociados, porque en tal situación, éstos están obligados, según inciso k) del artículo 6 de la LAC, a realizar un pago diferente, reza el inciso indicado:

k) Para efectos de calcular el impuesto sobre la renta, de los asociados de las cooperativas se tomará en cuenta solo el $50 \%$ de los ingresos que provengan de los excedentes e intereses de sus certificados de aportación de las cuotas de inversión obtenidas en la cooperativa.

\section{Derechos económicos del asociado retirado o excluido de la cooperativa}

Si bien uno de los principios esenciales del Cooperativismo, es el Principio de libre adhesión a la cooperativa, cuya contrapartida es también la libre separación de la misma, en la mayoría de los casos revisados en la jurisprudencia de los tribunales, así como en los criterios legales emitidos por la Asesoría Legal del INFOCOOP, el asociado no tiene claros sus compromisos económicos con la cooperativa, desde su ingreso hasta la finalización asociativa.

El derecho al reintegro o reembolso ha sido estudiado por García, A. ${ }^{3}$ entre otros autores del Derecho Cooperativo y lo considera como la restitución individual o devolución de los aportes iniciales al miembro que pierde su condición de tal, por cualquiera de las causas que fuese, aunque no se corresponda exactamente con lo que aportó a la empresa.

En apoyo a sus criterios, García ${ }^{4}$ (2017, p.104) cita a Pendón (2013): «En sentido estricto, no se trata de que el socio que causa baja tenga derecho a la devolución (reembolso) del capital aportado: la aportación a la cooperativa es un capital de riesgo (sometido al riesgo derivado del ejercicio de la actividad empresarial que realiza la cooperativa) que, por lo tanto, se ve necesariamente afectado por las vicisitudes que experimente el patrimonio social; la liquidación exige que

3 GARCÍA MULLER, A. (2016). Derecho cooperativo y de Economía Social y Solidaria. .Módulo 4. Régimen económico. Ed. Asociación iberoamericana de Derecho Cooperativo, Mutual y de la Economía Social y Solidaria. Venezuela, p. 104.

4 GARCÍA MULLER, A. (2016). Derecho cooperativo y de Economía Social y Solidaria. Módulo 4. Régimen económico p. 104. 
sobre la aportación se apliquen las pérdidas y las deducciones correspondientes, así como los incremento oportunos. En estos términos, el derecho de liquidación de las aportaciones se articulará según las correspondientes previsiones estatutarias».

Sobre la naturaleza jurídica del derecho a la devolución de los aportes a la cooperativa, García ${ }^{5}$ también se apoya en Viguera, (2011), autor que considera el tipo de derecho del socio cooperativo cuando explica:

Se trata de un derecho del socio, derecho de crédito que otorga al cooperativista un poder jurídico subjetivo, amparado por la Ley, que lo ostenta frente a la sociedad cooperativa que resulta ser la obligada; derecho subjetivo del que es titular el socio-acreedor, por el que puede exigir del deudor (la cooperativa) la realización de un determinado comportamiento.

Para García, no recae sobre la persona del deudor, sino sobre la actividad que éste debe desplegar para la realización de la prestación, o sobre las consecuencias de su incumplimiento, cuya efectividad se asegura con la responsabilidad del patrimonio del deudor. En principio, al momento de la pérdida de la condición las aportaciones del miembro dejan de formar parte del capital social y se transforman en un pasivo exigible (como una acreencia de tercero) por lo que no pueden correr la suerte del resto del capital, que puede o no percibir intereses. Sin embargo, si así lo permite el estatuto, la empresa puede negarse a reintegrar el total o parte de los aportes, siendo considerados estos como patrimonio neto de la empresa.

García ${ }^{6}$ disgrega varias características de los derechos económicos derivados del derecho al retiro que integran muchos de los preceptos que las normas de la LAC ha tomado en cuenta para determinar su naturaleza jurídica y los límites del ejercicio de tal derecho, se apuntan las características dadas por el autor:

1. El reintegro es un derecho firme, aunque puede quedarse como una mera expectativa de derecho cuando se trate de aportaciones cuyo reembolso puede rehusar el órgano directivo, si así lo permite el estatuto.

2. No contingente, pues el socio tiene ese derecho desde que ingresa, y se mantiene en todo momento, aunque pueda suspenderse su efectividad de manera excepcional.

5 Ibid., p. 108.

6 Ibid., p. 106. 
3. De contenido patrimonial, naturalmente pecuniario, fruto de una valoración realizada sobre la suma a que asciende su aportación, disminuida o aumentada de acuerdo a la situación financiera de la empresa.

4. Inatacable, en cuanto que como derecho firme, convierte al ex miembro en acreedor de la entidad, ya que desde el punto de vista contable, se considera como una partida del pasivo de la empresa.

Las normas legales de la LAC son claras tanto en el artículo 10 que considera que no existe lesión al derecho de libre asociación -Principio de libre adhesión a la cooperativa - y la reglamentación estatuaria del ejercicio del derecho al retiro. Ese artículo se complementa con el artículo 62 de la misma ley, en el cual se regula el derecho a los excedentes e intereses del ejercicio en curso hasta el momento de su retiro.

También se reconocen otros derechos al asociado que se retire o fuere excluido de la cooperativa:

- Al finalizar el ejercicio económico, el importe neto se le entregará, en la forma y condiciones que dispongan los estatutos;

- El asociado en esa condición, tendrá derecho a que se le devuelva íntegramente el monto de los aportes pagados por él menos los saldos que deba a la cooperativa y la proporción que le corresponde en las pérdidas del patrimonio social, si las hubiere, en la forma y condiciones que dispongan los estatutos. La situación de deudas del asociado con su cooperativa lleva también a revisar la garantía que la LAC reconoce desde el origen de la relación asociativa tienen los certificados de aportación, en el tanto que están vinculados en forma preferente a favor de la cooperativa; además de depósitos, participaciones o derechos de cualquier clase que correspondan a los asociados de una cooperativa, como garantía de la obligación u obligaciones que aquellos pudieran llegar a tener con la asociación (artículo 70 de LAC).

García ${ }^{7}$ también ofrece elementos de la forma de calcular el reintegro:

El valor de liquidación de las aportaciones se obtendrá a partir del balance de cierre del ejercicio social en que se haya originado el derecho de reembolso, teniendo los miembros el derecho a recibir íntegramente las aportaciones que realizaron en su día y actualizadas, si

7 Ibid., p. 108. 
el estatuto no lo autoriza, prohibiéndose aplicar deducciones no previstas en la ley y, o en el estatuto. Lo procedente es que se pueda hacer mediante la compensación de los activos (aportes, derechos y excedentes no cobrados) con los pasivos del miembro en la empresa (deudas y obligaciones pendientes).

Esa vinculación preferente a veces no es conocida por los asociados, en el caso de una cooperativa de intermediación financiera, una asociada retirada consultó a la Asesoría Legal del INFOCOOP, SC-0815148-2011, 19 de setiembre del 2011, y se reiteraron sus obligaciones económicas con la cooperativa que le había otorgado el préstamo, considerando que el origen del dinero provenía del aporte de todos los asociados para que el asociado-deudor pueda resolver determinadas necesidades financieras. En particular, en las empresas de ahorro y crédito cooperativas, esta confianza es de especial relevancia por la relación entre el capital que se presta y los aportes de los asociados, quienes finalmente son los dueños de la empresa. Y un dato de interés que también aporta ese ente, es que considera oportuno que en el contrato de préstamo se incluya la condición estatutaria sobre la responsabilidad de los certificados de aportación y otros instrumentos de crédito mencionados.

\section{Derecho al retiro cooperativa autogestionaria}

Cuando un asociado-trabajador de una cooperativa autogestionaria ejerce el derecho al retiro, tiene los mismos derechos que un asociado en una cooperativa de otra clase, por esa razón, no deben cancelarse los extremos laborales (preaviso y cesantía entre otros), sino más bien debe hacerse entrega de los extremos a que hace referencia el artículo 62 de la LAC, como son la devolución del capital social, así como los excedentes e intereses del último periodo si los hubiera. El INFOCOOP ha reiterado su criterio sobre la compensación de deudas con capital social en el criterio emitido bajo el número SC-924-59-2011:

En cuanto al tratamiento del primer tema, sea la compensación de deudas, debemos iniciar por analizar lo referente al tema de la devolución de «capital social», que es el término técnico utilizado para referirse al «ahorro obligatorio».

Al respecto debemos manifestarle que la devolución del capital social y otras sumas, debe producirse al finalizar el vínculo asociativo con una Cooperativa, y se encuentra regulada en los artículos 62 y 72 de la LAC.P 6. Por tanto, la devolución del capital social a que 
tienen derecho los asociados que se retiran de la cooperativa, ya sea por renuncia o expulsión, tiene que realizarse una vez finalizado el ejercicio económico de la cooperativa, siempre y cuando se haya presentado la renuncia formalmente antes de la finalización de dicho ejercicio. Para realizar la devolución debe contabilizarse hasta el día en que se renunció a la Cooperativa.

Asimismo, de existir excedentes o pérdidas en dicho periodo, solamente pueden ser tomados en cuenta por el tiempo transcurrido dentro del periodo anterior a su renuncia. Asimismo la Ley faculta a la Cooperativa, con el fin de evitar situaciones financieras difíciles, que establezca un porcentaje máximo de devoluciones al año, por lo que de no alcanzar la suma destinada a cubrir las devoluciones de capital por concepto de renuncias en un periodo económico, debe esperar a los siguientes periodos económicos en orden de precede.

\section{Inicio del plazo para el pago de los aportes a asociados retirados en una cooperativa}

García ${ }^{8}$ en cuanto al plazo para entregar los aportes y otros derechos que tenga un asociado retirado, apunta que: El plazo es establecido en beneficio exclusivo de la empresa, dirigido a evitar su descapitalización si tuviera que procederá un inmediato reintegro, dándole un tiempo para que pueda afrontar el coste económico que su pago le ocasiona.

En Costa Rica, correspondió a la Sala Segunda de la Corte Suprema de Justicia, por voto 00315-1996 revisar la sentencia del Tribunal Superior de Trabajo de Alajuela, a las 8:20 horas, del 16 de enero de este año, en el tanto contempla la confusión de diferentes normas de prescripción que reclamaron varios socios retirados de una cooperativa, ubicadas en el Código de Trabajo, Código de Comercio y Código Civil, a partir de la posibilidad ofrecida por el artículo 131 de la LAC, que hace extensiva la interpretación de la ley cooperativa a esos cuerpos normativos, en caso de laguna jurídica. La jueza redactora falló lo siguiente:

Al final, el juez superior concluyó que no era necesario revisar cual plazo de prescripción se aplicaría, en el tanto la Cooperativa deudora había reconocido su deuda y había establecido el plazo de cumplimiento, de tal modo que hasta que éste se cumpliera no podría iniciarse la cuenta de meses o años — según norma a elegirpara la prescripción.

8 Ibid., p. 108. 


\section{Desafiliación y conservación del patrimonio cooperativo}

También se ha dado la confusión entre el derecho al retiro por parte de un asociado a una cooperativa y su derecho a la devolución de sus aportes, denominados certificados de aportación y sus derechos accesorios, como serían los intereses generados en el período fiscal correspondiente. En la Sala Constitucional, mediante Voto 02630-2009, fue analizado el reclamo de un asociado que en el resultando II, se resume como:

OBJETO DEL RECURSO. El recurrente acude en tutela del derecho de asociación de la amparada, quien —aduce — ha solicitado en repetidas oportunidades, la desafiliación de la Cooperativa recurrida, no obstante, ello le ha sido negado bajo el argumento que tiene deudas pendientes con esa organización. Asimismo, alega que la recurrida detenta datos imprecisos respecto de la operación crediticia que mantiene la amparada con esa entidad, lo que estima, violatorio de su derecho a la autodeterminación informativa.

El antecedente se encuentra en la sentencia No. 1626-07 dictada por el Juzgado Primero Civil de Menor Cuantía que declaró con lugar el proceso de cobro planteado por una cooperativa en contra de la asociada que solicitó la desafiliación. También se dictó el embargo del salario de la afiliada para cubrir capital e intereses. En los estatutos de la cooperativa, existe una norma que condiciona la aceptación de la renuncia previo pago de las deudas existentes, y el transcurso de un mes, contado a partir de ese pago. La Sala Constitucional declaró con lugar el recurso de amparo con base en el derecho de asociación, pues resulta contrario al derecho de asociación en su dimensión negativa, pues no se permite la desafiliación de la tutelada en aras de resguardar el patrimonio de la entidad, toda vez que ésta tiene una deuda pendiente de cancelar.

\section{Sobre derecho a retiro sin previo pago de deudas}

La Sala Constitucional, en el mismo voto antes identificado, cita el voto: 02381-2006, que revisó alegatos similares, y basa en la solución reiterada de protección de los derechos de asociación, en el voto N: 02303-2001, así como la falta de competencia por razón de la materia, por parte de la Sala Constitucional, dado que el reclamo de recursos es un trámite de mera legalidad, revisable por los tribu- 
nales comunes y en aplicación de las normas estatutarias, en síntesis resolvió:

«...el reintegro o disposición de los aportes de los miembros que se retiran de una cooperativa se regula por las disposiciones internas de cada ente, es decir, conforme a sus estatutos, por lo que los conflictos que surjan al respecto deben resolverse de conformidad a los mismos, mediante los mecanismos y ante las instancias establecidas al respecto, o bien, ante la jurisdicción ordinaria correspondiente, pues ello es un asunto que no implica -en principio- aspectos propios de constitucionalidad, por el contrario, es cuestión de mera legalidad. Inclusive, si el recurrente estima que se está reteniendo indebidamente sus ahorros ello eventualmente puede llegar a configurar un delito, susceptible de ser conocido en vía penal pero no en ésta. (Ver en este sentido sentencia número 211-91 de las quince horas y dos minutos del treinta de enero de mil novecientos noventa y uno, número 700-92 de las dieciséis horas doce minutos del once de marzo de mil novecientos noventa y dos y número 4502-94 de las quince horas cincuenta y cuatro minutos del veintitrés de agosto de mil novecientos noventa y cuatro.)»

\section{Devolución de aportes a asociado en cooperativa cogestionaria}

Las cooperativas cogestionarias se caracterizan, según el Capítulo XII de la LAC, porque la propiedad, la gestión y los excedentes son compartidos entre los trabajadores y los productores de materia prima, entre el Estado y los trabajadores o entre los trabajadores, los productores de materia prima y el Estado (artículo 120). Pueden tener trabajadores que no sean asociados a la cooperativa, siempre y cuando cumplan con el porcentaje mínimo de $40 \%$ del total de trabajadoresasociados (artículo 123).

La situación planteada por un ex-asociado consistió en la falta de devolución de sus aportes, pues mensualmente se le rebajaba determinada suma de sus ingresos, obtenidos con la Cooperativa, además de la preocupación adicional, ante una consulta realizada en el Ministerio de Trabajo sobre sus derechos y la respuesta obtenida fue más preocupante, dado que le indicaron que el tiempo de prescripción de su derecho, era de un año y ya habían pasado 15 meses. En el Instituto nacional de fomento cooperativo, por medio de la oficina de Macroproceso, oficio de 10 de junio del 2010, MGS-566-83-2010, aclaró en primer lugar sobre la naturaleza jurídica de COOPEMONTECILLOS R.L. 
que es una cooperativa de modelo cogestionario, en la cual los trabajadores en su gran mayoría (al menos el 95\%) deben ser asociados de la cooperativa. Además se consideró la relación asociativa del consultante, y que por ello, se le rebajaba de su ingreso periódico una suma mensual como aporte de capital.

Lo interesante es que se encuentra la norma estatutaria que especifica un monto anual de los retiros anuales, en el caso de retiro, exclusión o fallecimiento de los asociados, artículo 10, que no puede ser superior al $2 \%$ del capital social cooperativo pagado. Esa limitación está autorizada por los artículos 62 y 72 LAC, donde se autorizan a las cooperativas a establecer porcentajes fijos como monto máximo a devolver al finalizar cada ejercicio económico. Se concluye que las consultas en ese sentido son reiteradas y que la LAC no deja dudas sobre su solución.

\section{Conclusiones}

La legislación costarricense contempla la totalidad de situaciones jurídicas relativas al ejercicio de los derechos económicos de los asociados de una cooperativa. Mientras se mantiene la relación asociativa no existe gran duda sobre el disfrute de los beneficios provenientes de las ganancias del capital social, así como de la distribución de los excedentes. Ha correspondido a la Sala Constitucional dirimir los múltiples recursos de amparo interpuestos por los asociados de las cooperativas, sobre todo cuando solicitan la desafiliación de su cooperativa. El recurso se presenta ante la confusión entre los derechos asociativos y los derechos económicos, los cuales generalmente están regidos por normas legales de diferente rango, pues el derecho de asociación, además de constar en el artículo 25 de la Constitución Política costarricense, es el fundamento de la Ley de asociaciones cooperativas vigente; y contempla el derecho de asociación tanto para el ingreso como el retiro de un grupo asociativo.

Mientras que los derechos económicos están sujetos a los estatutos de las cooperativas, con una mejor definición de las normas legales, buscando protección tanto al patrimonio cooperativo como al patrimonio personal de los cooperativistas. Por esa razón, la devolución del valor de certificados de aportación está sujeta a la falta de pérdidas en la cooperativa correspondiente o bien, a la sujeción de plazos para no afectar la vida de los asociados que permanecen en la actividad económica y social que representa la cooperativa. 
Lo importante es que el derecho al retiro en una cooperativa puede ser objeto de reglamento, siempre y cuando las restricciones sean razonables y no arbitrarias. Dentro de lo razonable no hay duda que se encuentra la protección al patrimonio social cooperativo, y que por esa razón se justifica por ejemplo el establecimiento de porcentajes anuales, para la devolución de fondos a los ex asociados.

Si bien, existen algunas diferencias con la distribución de excedentes de las cooperativas tradicionales y las denominadas de autogestión y cogestión, en el tanto que tienen reglas especiales en cuanto a su distribución, todo asociado cooperativo tiene acceso a las ganancias de la gestión de la cooperativa, sea por su participación en forma directa o indirecta. En las cooperativas autogestionarias así como en el caso de los trabajadores en las cogestionarias, existe la entrega de los "anticipos laborales», como una especie de salario, que al final se suma a sus derechos a los beneficios económicos de cada período fiscal de la cooperativa.

La ausencia de actualización de la Ley de asociaciones cooperativas frente a las novedades incorporadas por la Alianza Cooperativa Internacional y el modelo de Ley marco para las Américas, se ha complementado con los votos de la Sala Constitucional y el cumplimiento de la función asignada al ente estatal que fomenta las cooperativas, de interpretar e integrar la ley cooperativa, como es el Instituto nacional de Fomento Cooperativo.

\section{Bibliografía}

BRETOS, I., DÍAZ-FONCEA, M., MARCUELLO, C. y MARCUELLO, CA. 2018. "Cooperativas, capital social y emprendimiento. Una perspectiva teórica. REVESCO. Revista de Estudios Cooperativos, núm. 128, pp. 76-98.

GADEA, E., SACRISTÁN, F. y VARGAS, C. 2009. Régimen jurídico de la sociedad cooperativa del siglo XXI. Realidad actual y propuestas de reforma. Ed. Dykinson S.L., Madrid.

GARCIA MULLER, A. 2016. Derecho cooperativo y de Economía Social y Solidaria. Módulo 4. Régimen económico. Ed. Asociación iberoamericana de Derecho Cooperativo, Mutual y de la Economía Social y Solidaria. Venezuela.

SÁNCHEZ BOZA, R. 2015. "Sistemas de crédito cooperativo: defensa del modelo». Boletín de la Asociación Internacional de Derecho Cooperativo, núm. 49, pp. 31-48. doi: http://dx.doi.org/10.18543/baidc-492015pp31-48 
Criterios legales del Instituto Nacional de Fomento Cooperativo (todos recuperados el 30 de marzo de 2018)

TRANSMISIÓN CAPITAL

SC 1408-1404CO-2015. http://www.infocoop.go.cr/nuestros_servicios/ supervision/jurisprudencia/3CapitalSC \%201408-1404CO-2015.pdf

EXCEDENTES PROVENIENTES ORGANISMOS DE INTEGRACIÓN

AL 668-93 del 21 de setiembre de 1993. http://www.infocoop.go.cr/nuestros_ servicios/supervision.html

Devolución Fondos Asociado Cogestionario

MGS-566-83-2010. http://www.infocoop.go.cr/nuestros_servicios/supervision/ jurisprudencia/3CapitalSC\%201408-1404CO-2015.pdf

INGRESO GRAVABLE

SC-924-59-2011. http://www.infocoop.go.cr/nuestros_servicios/supervision/ jurisprudencia/7AutogestionSC-924-59-2011.pdf

DEVOLUCIÓN APORTES COGESTIÓN

MGS-566-83-2010. http://www.infocoop.go.cr/nuestros_servicios/supervision/ jurisprudencia/7CogestionMGS-566-83-2010.pdf

PAgO CUOTAS PATRONALES

SC-1077-944-2011. www.infocoop.go.cr/nuestros_servicios/supervision/ jurisprudencia/7CogestionSC-1077-944-2011.pdf

Reserva Bienestar Social pago fiestas

MGS-584-412-2007. http://www.infocoop.go.cr/nuestros_servicios/supervision/ jurisprudencia/3BienestarMGS-584-412-2007.pdf

\section{RETIRO}

SC-924-59-2011. http://www.infocoop.go.cr/nuestros_servicios/supervision. html

SC-0815-148-2011. http://www.infocoop.go.cr/nuestros_servicios/supervision. html 


\section{Leyes}

CÓDIGO DE TRABAJO (1943). Ley. N. 2, 27 de agosto de 1943, http://www. pgrweb.go.cr/scij/Busqueda/Normativa/Normas/nrm_texto_completo. aspx?nValor1=1\&nValor2=8045 Recuperado el 25 de abril de 2018.

ASAMBLEA LEGISLATIVA (1994). Ley de intermediación financiera de cooperativas de ahorro y crédito N. 7391 de 22 de abril de 1994. http://www. pgrweb.go.cr/scij/Busqueda/Normativa/Normas/nrm_texto_completo.aspx ?param1=NRTC\&nValor1=1\&nValor2=1 1935\&nValor3=93291\&strTipM= TC. Recuperado el 28 mayo de 2018.

ASAMBLEA LEGISLATIVA (1968). Ley de asociaciones cooperativas N. 4179. http://www.pgrweb.go.cr/scij/Busqueda/Normativa/Normas/nrm_texto_ completo. aspx? param $1=$ NRTC \&nValor $1=1 \&$ nValor $2=32655 \&$ nValor3= 85395\&strTipM=TC. Recuperado el 30 de marzo de 2018.

\section{Sentencias de tribunales: la Sala Constitucional}

VOTO 02381-2006. http://jurisprudencia.poder-judicial.go.cr/SCIJ_PJ/busqueda/ jurisprudencia/jur_Documento.aspx?param 1=Detalle_Sentencia\&param $2=2 \&$ nValor $1=1 \& n$ Valor $2=339512 \&$ nValor $3=108439 \&$ tem $1=$ Asociaci $\%$ C3\%B3n\%20cooperativa\&strTipM=E1\&|Resultado=17\&strTem=ReTem. Recuperado el 22 de marzo de 2018

VOTOS N, 02381-2006 y N. 02630-2009 (2006-2009). http://jurisprudencia. poder-judicial.go.cr/SCIJ_PJ/busqueda/jurisprudencia/jur_Documento. aspx? param 1=Detalle_Sentencia\&param2=1\&nValor $1=1 \&$ nValor $2=44566$ 4\&nValor3=127663\&tem 1=Asociaci\%C3\%B3n\%20cooperativa\&strTipM= E1\&IResultado=6\&strTem=ReTem Recuperado el 22 de marzo de 2018.

VOTO 10773-2007. http://jurisprudencia.poder-judicial.go.cr/SCIJ_PJ/busqueda/ jurisprudencia/jur_Documento.aspx?param1=Detalle_Sentencia\&param2= 1\&nValor1=1\&nValor2=399067\&nValor3=122916\&tem 1=Asociaci\%C3\% B3n\%20cooperativa\&strTipM=E1\&|Resultado=8\&strTem=ReTem. Recuperado el 22 de marzo de 2018.

VOTO 11629-2010. http://jurisprudencia.poder-judicial.go.cr/SCIJ_PJ/busqueda/ jurisprudencia/jur_Documento.aspx?param1=Detalle_Sentencia\&param2= 1\&nValor $1=1 \&$ nValor2=501018\&nValor3=134651\&tem $1=$ Asociaci $\%$ C3\% B3n\%20cooperativa\&strTipM=E1\&|Resultado=4\&strTem=ReTem. Recuperado el 30 de marzo de 2018.

SALA SEGUNDA DE LA CORTE SUPREMA DE JUSTICIA, por Voto 00315-1996 http://jurisprudencia.poder-judicial.go.cr/SCIJ_PJ/busqueda/jurisprudencia/ jur_Documento. aspx?param 1=Detalle_Sentencia\&param2=8\&nValor $1=1$ \&nValor2=24438\&nValor3=61695\&tem $1=$ Asociaci $\%$ C3\%B3n\%20coope rativa\&strTipM=E1\&|Resultado=77\&strTem=ReTem. Recuperado el 22 de marzo de 2018. 
Dictámenes de la Procuraduría General de la República

DICTAMEN C-007-91 del 14 de enero de 1991 citado en criterio de INFOCOOP. http://www.infocoop.go.cr/nuestros_servicios/supervision/ jurisprudencia/3BienestarMGS-584-412-2007.pdf Recuperado el 22 de marzo de 2018. 


\section{Derechos de autor}

El Boletín de la Asociación Internacional de Derecho Cooperativo es una revista de acceso abierto lo que significa que es de libre acceso en su integridad inmediatamente después de la publicación de cada número. Se permite su lectura, la búsqueda, descarga, distribución y reutilización legal en cualquier tipo de soporte sólo para fines no comerciales y según lo previsto por la ley; sin la previa autorización de la Editorial (Universidad de Deusto) o el autor, siempre que la obra original sea debidamente citada (número, año, páginas y DOI si procede) y cualquier cambio en el original esté claramente indicado.

\section{Copyright}

The International Association of Cooperative Law Journal is an Open Access journal which means that it is free for full and immediate access, reading, search, download, distribution, and lawful reuse in any medium only for non-commercial purposes, without prior permission from the Publisher or the author; provided the original work is properly cited and any changes to the original are clearly indicated. 